\title{
The Meaning of the Phytotoxicity of the Soils of Transformational Landscapes in the Southeast of Russia
}

\author{
Nikolai Larionov \\ School No.2 Urban District Kotelniki \\ Novaya Street, 39 \\ Kotelniki, Moscow region, Russian Federation 140054
}

\section{Irina Siraeva}

Saratov State University

Astrakhanskaya Street, 83

Saratov, Russian Federation 410012

Anna Ermolenko

Saratov State University

Astrakhanskaya Street, 83

Saratov, Russian Federation 410012

\author{
Maxim Larionov \\ Balashov Institute of Saratov State University \\ K. Marx Street, 29 \\ Balashov, Saratov region, Russian Federation 412300 \\ E-mail: m.larionow2014@yandex.ru
}

Tatiana Gromova

Saratov State University

Astrakhanskaya Street, 83

Saratov, Russian Federation 410012

Tatiana Zavidovskaya

Borisoglebsk Branch of Voronezh State University

Narodnaya Street, 43

Borisoglebsk, Russian Federation 397160

\begin{abstract}
The levels of the phytotoxicity of soils in different territorial objects of urban landscapes in the south east of Russia (using the example of towns of Saratov and Voronezh regions) are defined. The levels of degradation of soils using the indicators of phytotoxicity are defined with singling out zones of ecological trouble. A conclusion is made about a necessity of ensuring ecological safety in the zones of joint influence of motor transport and stationary sources of pollution of Saratov and Voronezh regions in the context of normalization of the current ecological situation, first of all, on roadside territories. The parameters of phytotoxicity in this case serve as reliable ecological and diagnostic criteria of the control of quality of the soil covering of functional and planning structures adjoining to traffic ways.
\end{abstract}

Keywords-urban landscapes; technogenic process; degradation of soils; meanings of phytotoxicity; ecologically problematic zones; ecological safety

\section{INTRODUCTION}

Transformational landscapes in contrast to natural possess characteristics formed on the basis of natural components - soils, geological basis, reservoir, etc. These characteristics, as such, are the consequences of technospheric and economical reclamation of environment for the needs of society. New economical, architectural and planning, engineering and technical solutions of arrangement of territories and its use are introduced, but often without taking into consideration ecological requirements.
Unfortunately, the areas of transformational landscapes are constantly expanding especially because of expanding transport net, environmental management, the development of agriculture, in the process of urbanization. Technogenic pressing on environment is generally increasing both in Russia and in the world [1] [2] [3] [4] [5] [6] [7] [8] [9] [10] [11] [12] [13]. Especially strong it manifests itself in such transformational landscapes as cities and their suburban districts [14] [15].

Evident crisis ecological phenomena are connected with the loss of resource meaning by many urbanized districts and a general decline in ecological situation in the central part of Russia as well as in its south-eastern regions.

At present in the towns of Saratov and Voronezh regions there appear a great variety of ecologically problematic situations. Most of them are directly and indirectly connected with emissions and waste products from movable sources of pollution (in the first place from motor transport) and also from the activities of industrial, communal and other stationary objects ensuring emission of technogenic admixtures of different power and in their composition harmful substances into atmosphere and soil covering. Often the chemical pollution of the components of environment by movable and stationary sources in definite functional zones happen together which was found at the previous stage of ecomonitoring research [16] [17] [18]. That strengthens the effect of reducing the quality of objects of environment and the degradation of their inert and bioinert and, unfortunately, living components. 
As a result, within towns the basic ecological frames are strongly suffering, the frames formed by fragile phytocenoses from green planting by soil covering and reservoirs, the reason of which is, as shown above, a joint negative ecological influence of an urbanistic complex.

In suburban districts both transport and economical pressing and the consequences of agricultural activities have an impact of the condition and qualities of soils.

By present there has taken a shape a necessity of differentiating technogenic pressing into urban landscapes according to functional and planning zones: living, social and business, industrial, transport and a number of other town territories.

Soils and vegetation cover comprise the structural and functional basis for ecological frames of settlements and are the indicators of stability and specific features of anthropogenic changes of ground urban landscapes. The enumerated one is very important, as a whole, for fundamental ecology in terms of research of mechanisms and regularities of functioning of artificial biogeocoenoses and also for a further wide practical use of this knowledge including in terms of creating stable town plantings and in the system of ecological evaluation of influences on environment.

The purpose of the research - finding out the level of technogenic pressing on different districts of urban landscapes depending on their location and economical use by way of determining the indicator of phytotoxicity of soils.

\section{THE MATERIALS AND METHODS OF RESEARCH}

In the territorial structure of the towns of Saratov and Voronezh regions we investigated the following objects: lawn of street and road network (roadside areas), roadside areas of suburban highways, areas adjoining to traffic ways and industrial enterprises (located as part of building zones), adjoining territories (lawns) to traffic ways and communal infrastructure, adjoining territories (lawns) to traffic ways and objects of public use (educational, social, cultural, hospitals, commercial enterprises, etc.), lawns of recreational objects (parks, squares, boulevards), territories around multi-storeyed residential facilities, adjoining districts to low-rise residential areas.

The ecological diagnostics of town soils can be made according to different criteria. In the give case we analyze the results of determining the phytotoxicity of the plots of unsealed soil covering in the zones of polluting influence of movable and unmovable objects of a town. This ecological indicator demonstrates the limiting meaning of the technogenic and chemical factor towards plants. In the given case the seedling method is used [19]. Biotest-organisms which we analyzed for toxicity of town soils were used for studying young crops Medicago sativa L., Avena sativa L. We used their seedlings obtained from previously planted in the samples of potting soils from the territories under study (shown in the histograms of pictures 1-4 absciss direction) for defining morphometric parameters (the length of aboveground parts, the length of underground parts, sm), the mass (mg) of aboveground and underground parts, the energy of germinating, the rate of lowering of germinating ability and the energy of germinating. The phytotoxicity was analyzed in the final evaluation scores: from 1 to 1,5 scores low phytotoxicity, from 1,6 to 2,5 - middle phytotoxicity, from 2,6 to 3,5 - advanced phytotoxicity, from 3,6 to $4-$ high phytotoxicity. The results were compared with the control for which we used samples of soils selected in relatively preserved out of town steppe biogeocoenoses not utilized by economical activities. For each town we took into account their own date according to soil sampling and, accordingly, the indicators of their phytotoxicity.

\section{THE RESULTS OF THE RESEARCH AND THEIR DISCUSSION}

We obtained average-weighted results of defining the phytotoxicity of the soil covering in the towns of Saratov region - Arkadak (population 11,9 people) and Balashov (population 77,3 people), in the towns of Voronezh regions Buturlinovka (24,6 people) and Novokhopyorsk (population 6,3 people) which are district centres.

The arithmetic mean data of the parameters of the phytotoxicity of the soil covering of the town of Arkadak showed the "Fig. 1" 


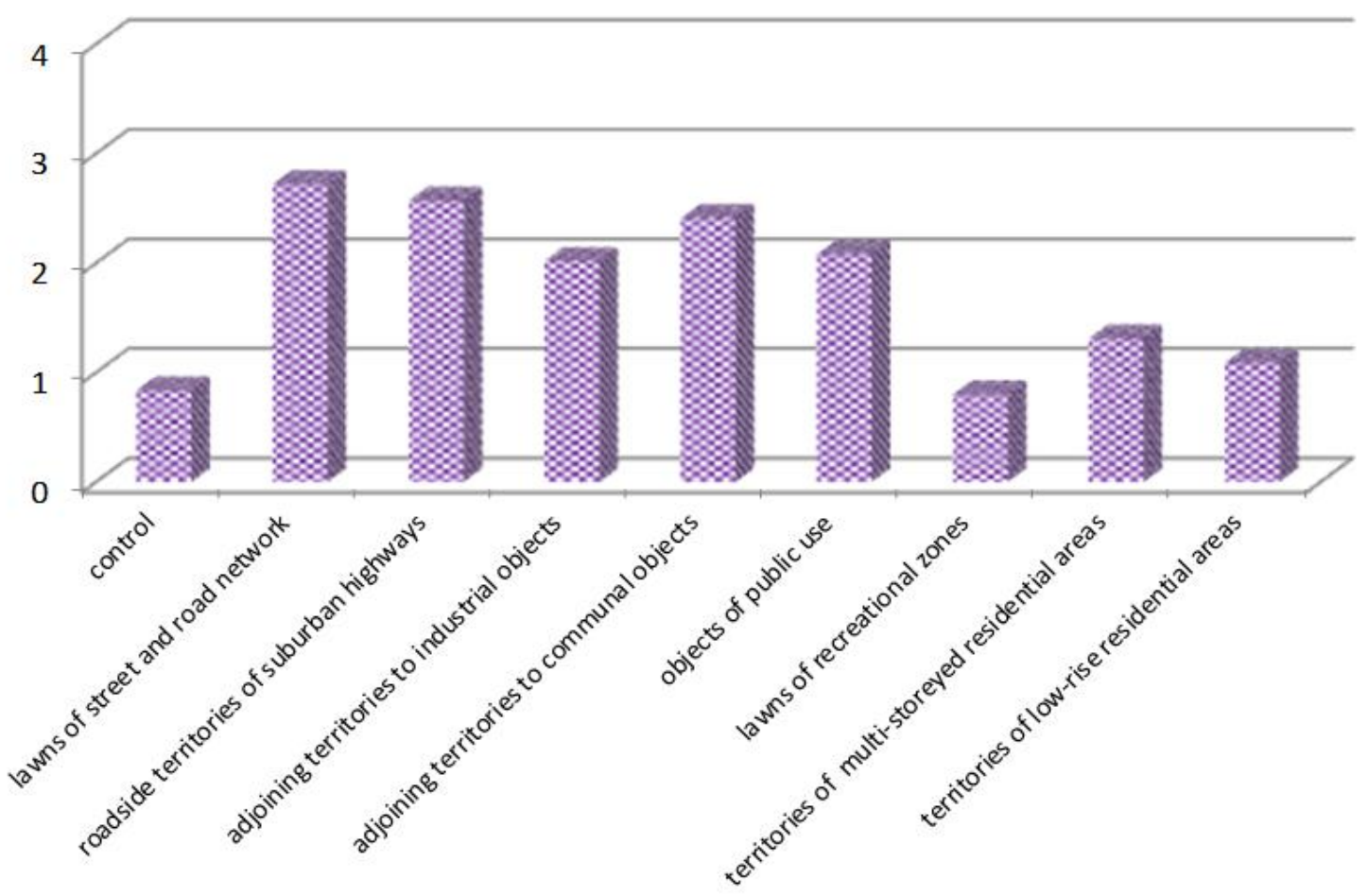

Fig. 1. The average-weighted values of the scores of degradation of the soil medium of Arkadak (2011-2018).

In the control conditions (out of town steppe biogeocoenoses) there established a low phytotoxicity of the soil samplings $(0,84 \pm 0,035$ scores $)$, which demonstrate, consequently, a low level of degradation of the preserved out of town steppe biogeocoenoses. On the territories of low-rise residential areas within the zones of technogenic influence of motor ways the value of phytotoxicity of the soils was revealed at the level of $1,09 \pm 0,033$ scores which can be characterized as a low phytotoxicity. Also the low level of phytotoxicity $(0,80 \pm 0,032$ scores $)$ is characterized of the soils of recreational territories. The other variants of phytotoxicity correspond to the average and advanced values. The advanced phytotoxicity of the soil covering corresponds to roadside territories of suburban highways $(2,57 \pm 0,071$ scores), adjoining territories to traffic ways and industrial objects $(2,72 \pm 0,085$ scores), lawns of social and business territories $(2,41 \pm 0,068$ scores), adjoining territories to motor ways and zones of multi-storeyed residential areas (1,31 $\pm 0,047$ scores). The advanced phytotoxicity is revealed in the samples of potting soil selected from the lawn plots of the street and road network (2,72 $\pm 0,083$ scores) and from the adjoining territories to roads and objects of the communal services $(2,41 \pm 0,072$ scores $)$. The differences of the parameters of phytotoxicity with the control are valid $(\mathrm{p}<0,05)$.

In Balashov in "Fig. 2", the phytotoxicity of the soil medium at the level of a low indicator corresponds to the control $(1,23 \pm 0,046$ scores $)$, recreational territories $(1,45 \pm 0,054$ scores). The advanced phytotoxicity was defined for the samples of the soils selected for the period of the research from the roadside areas bordering on the roads of suburban traffic $(2,47 \pm 0,074$ scores), adjoining districts to the motor ways and industrial enterprises $(2,26 \pm 0,091$ scores), the lawns adjoining to the areas of motor ways and communal objects $(3,31 \pm 0,14$ scores $)$, the lawns adjoining to the traffic ways and social and business institutions $(2,6 \pm 0,093$ scores $)$, multi-storeyed $(2,35 \pm 0,073$ scores $)$ and low-rise $(1,9 \pm 0,057$ scores) zones of residential construction. A high phytotoxicity $(3,63 \pm 0$,scores $)$ was marked for the lawn soils of the street and road network (along the motor ways). The differences of the parameters of the phytotoxicity of the soil sampling of the analyzed territorial structures with the corresponding control indicator are in statistically significant interval $(\mathrm{p}<0,05)$. 


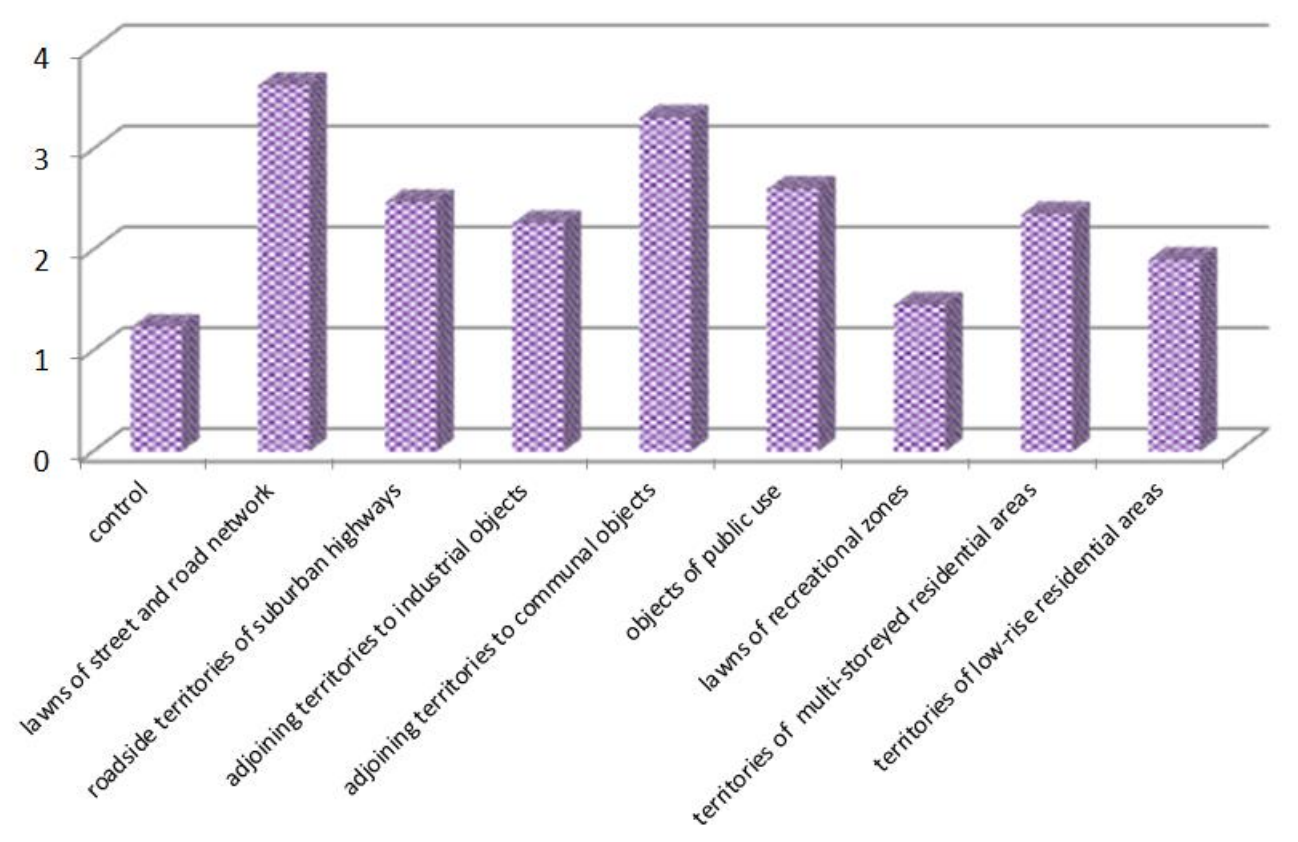

Fig. 2. The average-weighted values of the scores of degradation of the soil medium of Balashov (2011-2018).

Among the investigated settlements Balashov has the highest level of urbanization and a joint technogenic pressing (in comparison with Arkadak in Saratov region) on environment and soil covering, in particular. Consequently, within the investigated territorial objects the maximum indicators of the phytotoxicity of soil medium are revealed.

Within the town of Arkadak we revealed two ecologically problematic zones: the adjoining territories with the lawns along the street and road network and the adjoining territories to the motor ways and the objects of communal infrastructure.
In Balashov there are two of such categories: adjoining areas with the lawns along the street and road network and the adjoining territories to the motor ways and communal objects.

Further there follow the processed results of defining the phytotoxicity of soils under the urbanized conditions of Voronezh region.

The results for the town of Buturlinovka are presented in "Fig. 3".

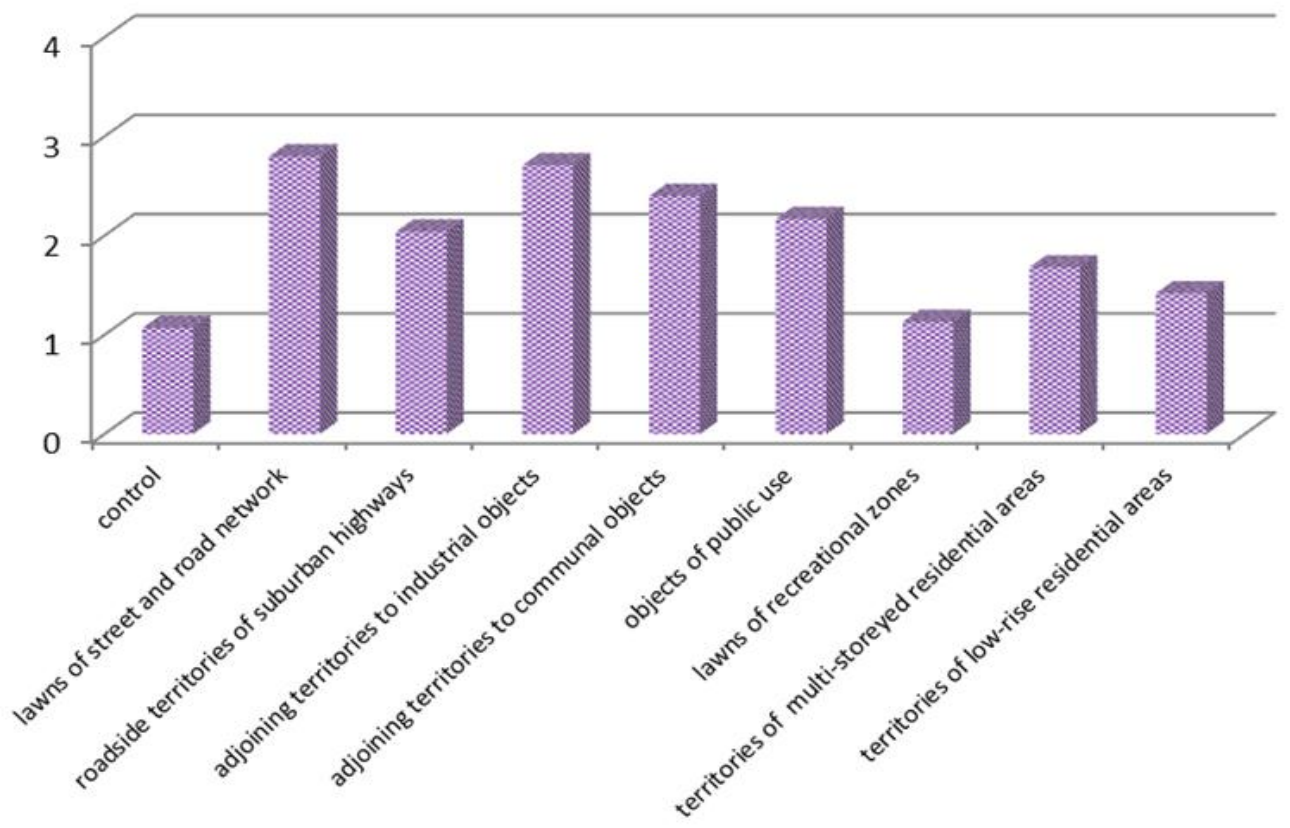

Fig. 3. The average-weighted values of the scores of degradation of the soil medium of Buturlinovka (2011-2018). 
The obtained data of the phytotoxicity of soils of the studied territories are statistically valid $(\mathrm{p}<0,05)$.

The minimal parameters of the phytotoxicity of soils are defined under the condition of the control $(1,07 \pm 0,035$ scores), the zones of recreation $(1,13 \pm 0,041$ scores) and the residential zones of low-rise $(1,42 \pm 0,057$ scores $)$. Here in the soils the level of phytotoxicity is low.

A higher level of phytotoxicity - middle - was found such territories: adjoining to motor ways of the territory of suburban highways $(2,04 \pm 0,078$ scores $)$, adjoining areas to the objects of communal economy $(2,40 \pm 0,083$ scores $)$, the social and business zones $(2,17 \pm 0,065$ zones), territories of multi-storeyed residential areas $(1,68 \pm 0,059$ scores $)$.

We revealed town territories with advanced values of the phytotoxicity of soil covering: the lawns of street and road system $(2,80 \pm 0,096$ scores), the adjoining districts to the industrial territories $(2,71 \pm 0,093$ scores $)$ which indicated at the ecological trouble of environment including the soil medium within these districts.

In Novokhopyorsk, a town smaller in the size and the population, in comparison with the previous place are found smaller values of phytotoxicity in "Fig. 4", but, nevertheless, the ones deserving attention.

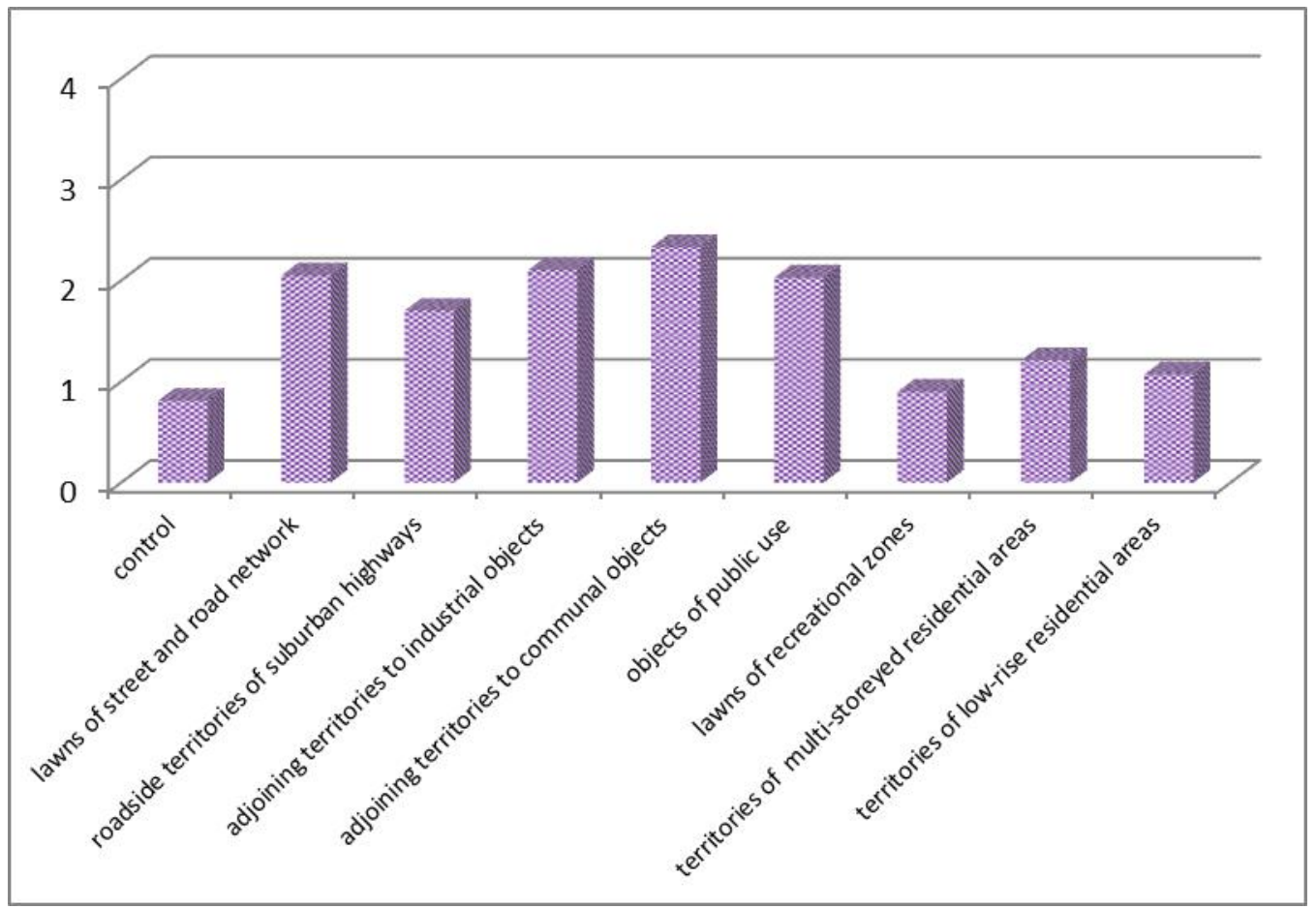

Fig. 4. The average-weighted values of the scores of degradation of the soil medium of Novokhopyorsk (2011-2018).

The minimal values of the analyzed ecological parameter are characteristic of the control zone $(0,81 \pm 0,033$ scores), the zones of recreation $(0,90 \pm 0,036$ scores $)$, multi-storeyed $(1,21 \pm 0,042$ scores $)$ and low-rise $(1,07 \pm 0,038$ scores $)$ residential areas.

The average degree of the phytotoxicity of soils are characteristic of the lawns of street and road network $(2,05 \pm 0,053$ scores $)$, roadside territories of suburban highways $(1,70 \pm 0,064$ scores), adjoining territories to industrial $(2,10 \pm 0,072$ scores $)$ and communal $(2,33 \pm 0,085$ scores) objects, the objects of public use $(2,03 \pm 0,078$ scores $)$. Those territories can also be related to the local zones of ecological trouble.

The found values of the phytotoxicity of soils of the given urbanized district with regard to the control indicator are statistically valid $(\mathrm{p}<0,05)$.

\section{CONCLUSION}

The joint factor of the transformation of landscapes under the condition of modern towns of the south-east of Russia has a direct impact on the condition of soils worsening their ecological indicators. The used ecological parameter phytotoxicity - is a reliable indicator of the condition of soils which allowed us to define their quality in different series of urban landscapes.

The transport and economical factor under the conditions of urban environment is toxic for herbaceous plants which, as a whole, limits the development of phytocenoses. The most oppressing plant value it reaches under the conditions of street traffic parts with motor ways, adjoining territories to industrial objects, adjoining territories to the objects of communal economy as well as under the conditions of social and business zones.

As follows for the obtained results, urban technogenic press ensures the manifestation of toxicity of soils in relation 
to plant bodies. In this case the value of the phytotoxicity of soil medium on different plots of residential areas demonstrate the corresponding level of their anthropotechnogenic degradation.

The minimal (low) level of anthropotechnogenic degradation of soil medium is characteristic of out of town steppe biogeocoenoses and the zones of recreation.

In the zones of technogenic and chemical influence of motor transport and motor transport together with stationary "suppliers" of contaminants into soil covering - adjoining to traffic ways territories with open soil covering occupied with lawn vegetation - the degree of anthropotechnogenic degradation of soil medium increases reaching average and advanced values. Those territories, first of all, areas with an advanced degree of the phytotoxicity of soil covering and, consequently, with an advanced level of the degradation of soil medium can be related to crisis ecological zones. That is characteristic of the all investigated settlements.

For the towns of Saratov and Voronezh regions there is a necessity of work on ensuring the control of the indicators of the phytotoxicity of different territorial objects, moreover on constant basis as well as measures on working out administrative and legal instruments for the effective management of the quality of environment, first of all, in the field of roadside systems.

A possibility of ensuring ecological safety and measures on its effective control need to be included in projects on reconstruction of landscape and architectural structures of urbanized territories including functional and planning zones and, as a whole, in town planning and environmental engineering. The criteria of changes in environment in the context of ensuring ecological safety and ecological management in urban landscapes of the south-east of Russia can be data of constant soil and ecological monitoring, in particular, the parameters of the phytotoxicity of soil covering.

\section{REFERENCES}

[1] Yu. M. Andriyanova and T. A. Druzhkina "The state of atmospheric air in the cities of the Saratov region", The Problems of ecology and nature management in the Middle Volga region: materials of the international scientific and practical conference devoted to the 140th anniversary of the birth of B. M. Zhitkov (Saransk, November 1-30, 2012). Saransk: Publishing house of Moscow state pedagogical University, 2013, pp. 76-80

[2] GOST 12038-84. "Seeds of agricultural crops. The method of determining germination". M.: Publishing standards, 1985, $57 \mathrm{p}$.

[3] A. J. Grigoryevskaya, L. A. Lepeshkina and D. S. Zelepukin "Flora of the Voronezh city district the city of Voronezh: bio-geographical, landscape-ecological, historical aspects", Samarskaya Luka: problems of regional and global ecology, 2012, vol. 21, No 1, pp. 5158.

[4] S. S. Derevyagin and I. F. Medvedev "Heavy metals in plant biomass and revegetation of chernozems of the Saratov region", Problems of increasing the efficiency of water and land resources of the Volga region: collection of scientific works. Saratov: Scientific book, 2011, pp. $148-152$.

[5] M. V. Larionov and N. V. Larionov "Dynamics of seasonal accumulation of lead in the leaves of woody plants in the urban environment", Bulletin of the Voronezh state University. Series: Chemistry. Biology. Pharmacy, 2015, No 2, pp. 51-54.

[6] M. V. Larionov "Complex assessment of technogenic pollution of urban areas of the Middle and Lower Volga region and progressive technologies aimed at its reduction": thesis of doctor of biological Sciences. Bryansk, 2013, 43 p.

[7] N. V. Larionov "Some results of the phytoindication of the ground-air environment in the towns of Rtischevo, Arkadak, the working village of Romanovka (Saratov region)", Food security: from dependence to independence": collection of materials of the all-Russian scientificpractical conference (Orel, November 29, 2017). Eagle: Publishing House OrelGAU, 2017, pp. 144-147.

[8] N. V. Larionov, M. V. Larionov and T. S. Gromova "Determination of ecological state of small urban systems of Saratov and Voronezh regions by methods of phyto-indexing", Urban Studies: research experience, modern practices, city development strategy: collection of materials of the all-Russian scientific-practical conference (Saratov, may 11-12, 2017). Saratov: SGTU Publishing house, 2017, pp. 150152.

[9] N. V. Larionov and M. V. Larionov "The Contents of some xenobiotics in the soil environment the recreational areas of the Saratov region", Innovation in science, 2015, No 43, pp. 34-41.

[10] F. N. Lisetskiy "Environmental problems and health of the population of the Voronezh region", Bulletin of the VSU. Series. Geography. Geoecology, 2010, No 2, P. 154-156.

[11] V. Z. Makarov, O. V. Surovtseva and A. N. Chumachenko "Estimation of dust content of the air basin of the city of Saratov according to direct and indirect methods of observations", News of Saratov University. New series. Series: Earth Science, 2014, vol. 14, No. 1 , pp. 16-25.

[12] On the state and environmental protection of the Saratov region in 2016. Saratov, 2016. $250 \mathrm{p}$

[13] M. A. Huston "Biological diversity. The coexistens of species on changing landscapes". Cambridg, 1994. $681 \mathrm{p}$.

[14] A. Kapicka, E. Petrovsky, P. Hrabak, V. Hoffman and M. Knab "Magnetic method of mapping industrially polluted soils", Proceedings of First International Conference on soils of Urban, Industrial, Traffic and Mining area, 2000, vol. 1, pp. 151-155.

[15] L. S. Ng, L. S. Chan, K. C. Lam and K. W. Chan "Heavy metal contents and magnetic properties of playground dust in Hong Kong", Environ. Monit. Assess, 2003, vol. 89 (3), pp. 221-232.

[16] M. V. Larionov and N. V. Larionov "Dynamics of seasonal accumulation of lead in the leaves of woody plants in the urban environment", Bulletin of the Voronezh state University. Series: Chemistry. Biology. Pharmacy, 2015, No 2, P. 52.

[17] M. V. Larionov "Complex assessment of technogenic pollution of urban areas of the Middle and Lower Volga region and progressive technologies aimed at its reduction": thesis of doctor of biological Sciences. Bryansk, 2013, P. 26.

[18] N. V. Larionov and M. V. Larionov "The Contents of some xenobiotics in the soil environment the recreational areas of the Saratov region", Innovation in science, 2015, No 43, P. 38.

[19] GOST 12038-84. "Seeds of agricultural crops. The method of determining germination". M.: Publishing standards, 1985, pp. 8-11. 